\title{
Newly Diagnosed Glioblastoma in Elderly Patients
}

\author{
Carlen A. Yuen ${ }^{1} \cdot$ Marissa Barbaro ${ }^{1,2} \cdot$ Aya Haggiagi $^{1,3}$
}

Accepted: 4 January 2022 / Published online: 5 February 2022

(C) The Author(s), under exclusive licence to Springer Science+Business Media, LLC, part of Springer Nature 2022, corrected publication 2022

\begin{abstract}
Purpose of Review Elderly patients with newly diagnosed glioblastoma (eGBM) carry a worse prognosis compared with their younger counterparts. eGBM garners special attention due to the unique challenges, including increased treatmentassociated toxicity, less relative benefit from aggressive therapy, medical comorbidities, and immunosuppression. The pivotal GBM trials excluded patients $>70$ years old and the optimal treatment approach remains unsettled for eGBM. In this review, we analyze the historical evidence-based data for treating eGBM and discuss the future direction for managing this vulnerable population.

Recent Findings Treatment for eGBM continues to evolve. Therapy choice is guided by performance status and presence of O6-methylguanine-DNA-methyltransferase (MGMT) promoter methylation. For eGBM with good performance status, combinatorial hypofractionated radiation therapy (hRT) and temozolomide should be recommended. For those with poor performance status, further stratification based on $M G M T$ promoter methylation test result is recommended. Single-agent temozolomide is a viable treatment option for MGMT methylated tumors (mMGMT); in particular, those classified with receptor tyrosine kinase II methylation. hRT alone can be considered in $M G M T$ unmethylated (uMGMT) eGBM patients. As precision oncology continues to advance, effective targeted and immunotherapy may emerge as new treatment options for eGBM.

Summary Management of elderly patients with newly diagnosed GBM carries a unique set of challenges. Progress has been made in defining the optimal therapeutic approach for these patients, but many questions remain to be answered.
\end{abstract}

Keywords Elderly $\cdot$ Glioblastoma $\cdot$ Hypofractionated radiation therapy $\cdot$ Temozolomide $\cdot$ Bevacizumab $\cdot$ Tumor-treating fields

This article is part of the Topical collection on Neuro-oncology

Aya Haggiagi

amh2237@cumc.columbia.edu

Carlen A. Yuen

cay2115@cumc.columbia.edu

Marissa Barbaro

marissa.barbaro@nyulangone.org

1 Division of Neuro-Oncology, Department of Neurology, Columbia University Vagelos College of Physicians and Surgeons, New York-Presbyterian Hospital, $710 \mathrm{~W}$ 168th St, 9th Floor, New York, NY 10032, USA

2 Present Address: Perlmutter Cancer Center at NYU Langone Hematology Oncology Associates - Mineola, NYU Long Island School of Medicine, NYU Langone Health, Mineola, NY, USA

3 Herbert Irving Comprehensive Cancer Center, Columbia University Vagelos College of Physicians and Surgeons, New York-Presbyterian Hospital, New York, NY, USA

\section{Introduction}

Glioblastoma (GBM) is the most common malignant primary brain tumor with an age-adjusted incidence that increases with age. According to the most recent Central Brain Tumor Registry of the United States (CBTRUS) statistical report, the highest incidence of GBM occurs among patients $>75$ years of age [1]. Despite representing the age group with the highest incidence of GBM, elderly patients with newly diagnosed GBM (nd eGBM) have been underrepresented in prospective studies. Both the landmark Stupp et al. trial [2] and the most commonly utilized prognostic schema for malignant gliomas excluded patients $>$ 70 years of age [3]. This unmet need was later recognized, and clinical trials were subsequently conducted specifically for eGBM. Though progress has been made, many questions are unanswered, including the age cut-off for defining "elderly" and equally as important, the optimal treatment for 
eGBM. Age has been the most significant predictor of treatment decision-making, which is driven by frailty, increased comorbidities, and increased risk of toxicity [4-7]. Due to these unique challenges, eGBM patients have been treated with less aggressive therapy [7-12], which may have altered their outcome. In this review, we analyze the current treatment approaches for nd eGBM and explore the questions that remain open for future investigation.

\section{Molecular Signature of GBM in Older Adults}

The poorer prognosis observed in eGBM has been attributed in part to the comorbidities that accompany advancing age. However, further disparities between older and younger patients can be due to differences in the intrinsic properties of eGBM, including the tumors' molecular characteristics and mutations. The proneural GBM subtype is associated with improved prognosis [13], but is an uncommon entity in eGBM [14]. eGBM lack the isocitrate dehydrogenase (IDH) mutations [15] that confer survival advantage [16, 17] and are rarely found in gliomas of older patients [17-19]. Only 3 of 126 gliomas of older patients in the Neurooncology Working Group (NOA) of the German Cancer Society Study 8 (NOA-08) [20] and 2 of 299 gliomas of older patients in the Nordic trials were found to have an $I D H ~ R 132 H$ mutation [21]. Additionally, in a cost-effectiveness study conducted by DeWitt et al., only 2 of 1023 GBM $\geq 55$ years of age were found to have a non-canonical $I D H$ mutation, suggesting that sequencing testing based on age can be considered [22]. Though the authors found low value in screening for a non-canonical $I D H$ mutation in older GBM patients, the authors also recognized that molecular testing in older patients can provide meaningful information [22].

The O6-methylguanine-DNA methyltransferase (MGMT) gene encodes an enzyme involved in DNA repair [20] and has a significant prognostic impact in GBM [23]. Hypermethylation of the MGMT gene promoter (mMGMT) silences the gene [23] and is found in up to 45 to $57.8 \%$ of eGBM $[24,25]$. The Nordic trial showed survival advantage for $\mathrm{m} M G M T$ tumors compared to uMGMT with an increase in OS of 9.7 months vs. 6.8 months for eGBM [21]. The NOA-08 trial showed similar findings with improved OS of 11.9 months vs. 8.2 months in mMGMT compared to $\mathrm{u} M G M T$ in eGBM [20]. Taken together, $M G M T$ is a strong independent prognostic biomarker for eGBM patients [23, 26]. Nevertheless, it is important to note that data from NOA-08 trial were immature at initial publication with median OS documented for only $61.1 \%$ of patients [20].

$\mathrm{m} M G M T$ also plays a strong predictive role as a marker of response to alkylating therapy. mMGMT abrogates the effects of alkylating chemotherapy by rendering the cancer cell unable to repair induced DNA damage [23].
Accordingly, mMGMT status is correlative with temozolomide (TMZ) sensitivity [20, 21, 23, 26].

More recent studies exploring genomic alterations associated with the eGBM molecular underpinnings [27] have found that tumor protein (TP)53 mutations [28], somatic copy number alterations, cyclin-dependent kinase $(C D K) 4$ amplification [29], $C D K N 2 A / p 16$ alterations [28], telomerase reverse transcriptase (TERT) promoter mutations [30], epidermal growth factor receptor $(E G F R)$ alterations, chromosome 7 gain, $9 p$ loss and $13 \mathrm{q}$ loss [31] are negative prognostic factors for eGBM. TERT gain-of-function promoter mutations occur more commonly in elderly gliomas [29, 32]. In 2018, Sasaki et al. performed a retrospective study on 140 elderly gliomas and found that presence of TERT promoter mutation was associated with decreased survival [33]. TERT promoter mutations have also been newly identified as molecular criteria for aggressive behavior in the new 2021 WHO Classification of Tumors of the Central Nervous System, in addition to and EGFR amplification [15, 34]. While theoretically these unfavorable eGBM specific molecular alterations can be capitalized upon, no targeted therapy has been proven to be beneficial in eGBM to date. In contrast to these eGBM negative prognostic factors, other studies have found favorable prognostic markers in eGBM, including anti-vascular endothelial growth factor (VEGF) [27]. Alpha thalassemia $\mathrm{X}$-linked intellectual disability syndrome gene $(A T R X)$ alterations are also associated with favorable prognosis, but are uncommon in older GBM patients [35]. Further studies to evaluate the impact of molecular biomarkers on the prognosis of eGBM will lead to better understanding of the basis for age-specific outcome differences and development of novel therapeutic targets.

\section{Surgery}

eGBM inherently carry a worse prognosis compared to their younger counterparts $[8,18,36]$, which has historically hindered the decision to operate on these patients [12, 37]. While post-operative seizures and delirium in eGBM patients were reported in one study [6], other studies found no increase in surgical complications with extensive resection compared to biopsy in eGBM [38-41]. Moreover, extent of resection improves OS in eGBM [20, 21, 38, 42-44], and older age alone should not be exclusionary for aggressive surgery [45]. A retrospective study conducted by Chaichana et al. found that extensive resection improved OS compared to biopsy in 40 eGBM older than $>65$ years and even in patients $>70$ years [38]. Another long-term retrospective study by Heiland et al. between 2008 and 2017 of 341 eGBM > 65 years showed that the longest median OS was associated with patients who underwent gross total resection, compared to partial resection or biopsy (10.8 months, 
8.1 months, and 3.0 months, respectively, $p \leq 0.001$ ) [46]. The 2020 guidelines for nd GBM recommend GTR for eGBM based on level III evidence [47]. In summary, current evidence is convincing for survival benefit with maximal safe surgical resection in this population [37, 39, 48], and older age alone should not preclude eGBM from aggressive surgery.

\section{Current Post-Operative Therapeutic Strategies}

While concurrent standard radiation therapy (sRT) consisting of $60 \mathrm{~Gy}$ in 30 fractions with daily TMZ followed by at least 6-months of adjuvant TMZ is the standard of care for younger patients with nd GBM, the optimal treatment for "elderly" patients remains unsettled as most randomized clinical trials (RCTs) until recently have excluded patients $>70$ years of age [2]. Historically, there has been interest in "de-intensifying" therapy for eGBM. This was driven by a need to balance the benefit of post-operative standard combination chemoradiation therapy with the risk of side effects in patients $>65$ years of age and in particular, those $>70$ years of age, with a low Karnofsky performance status (KPS) and multiple medical comorbidities. In the Stupp et al. trial, less apparent survival benefit was observed in patients $>60$ years of age (median survival 11.8 months with RT alone vs 10.9 months with combination therapy) [49]. However, the numbers were too small to draw firm conclusions. Notably to date, standard combination therapy has not been evaluated in RCTs for patients $>70$ years of age. Instead, radiation or TMZ monotherapy became a common alternative treatment strategy, particularly after the results of two key RCTs for this patient population were published in 2012 (NOA-08 and the Nordic trials), which compared single modality therapies. Prospective studies specifically designed for eGBM are summarized in Table 1.

\section{Radiation Therapy}

sRT delivered over 6 weeks provides a significant survival advantage over supportive care in eGBM [50] based on evidence from the Association des Neuro-Oncologues d'Expression Française (ANOCEF) trial (NCT00430911) that studied eGBM $>70$ years of age treated with biopsy or resection followed by sRT (50 Gy in 1.8 fractions) [50]. The authors also found that sRT had no adverse impact on cognition or quality of life (QoL) [50]. Conversely, other studies show poor adherence to a 6-week RT treatment schedule, with $19-26 \%$ of eGBM unable to tolerate the standard treatment time burden [21, 51, 52]. Hypofractionated RT (hRT) offers the benefit of a less intensive treatment schedule for eGBM. In 2004, Roa et al. investigated an abbreviated RT course ( 40 Gy in 15 fractions over 3 weeks) compared to the sRT course (60 Gy delivered in 30 fractions over 6 weeks). There was no difference in overall survival (OS) or QoL when hRT comparing to sRT, suggesting that an abbreviated RT course may be beneficial for eGBM with poor performance status and an expected short-term survival [51]. In 2012, the Nordic trial randomized 291 patients $>60$ years
Table 1 Elderly glioblastoma patient trials

\begin{tabular}{|c|c|c|c|c|c|}
\hline Study & Age & Patients & Treatment & Dosing regimen & $\begin{array}{l}\text { Median OS } \\
\text { (months) }\end{array}$ \\
\hline \multirow{6}{*}{$\begin{array}{l}\text { Nordic } \\
\text { Malmstrom et al. [20] }\end{array}$} & $\geq 60$ & 291 & TMZ & $5 / 28$ days & 8.3 \\
\hline & & & hRT & 34 Gy & 7.5 \\
\hline & & & RT & $60 \mathrm{~Gy}$ & 6.0 \\
\hline & $>70$ & 123 & TMZ & $5 / 28$ days & 9.0 \\
\hline & & & RT & $34 \mathrm{~Gy}$ & 7.0 \\
\hline & & & RT & $60 \mathrm{~Gy}$ & 5.2 \\
\hline \multirow{2}{*}{$\begin{array}{l}\text { NOA-08 } \\
\text { Wick et al. [19] }\end{array}$} & $>65$ & 373 & RT & $60 \mathrm{~Gy}$ & 9.6 \\
\hline & & & $\mathrm{TMZ}$ & 7 days on, 7 days off & 8.6 \\
\hline \multirow{2}{*}{$\begin{array}{l}\text { CCTG/EORTC } 26062 \\
\text { Perry et al. [64] }\end{array}$} & $>65$ & 562 & $\mathrm{RT}+\mathrm{TMZ}$ & $60 \mathrm{~Gy}$ & 5.3 \\
\hline & & & $\mathrm{RT}+\mathrm{TMZ}$ & $40 \mathrm{~Gy}$ & 9.3 \\
\hline \multirow{2}{*}{$\begin{array}{l}\text { ANOCEF trial } \\
\text { Keime-Guibert et al. [50] }\end{array}$} & $\geq 70$ & 85 & RT & $50 \mathrm{~Gy}$ & 6.7 \\
\hline & & & Supportive care & & 3.9 \\
\hline
\end{tabular}

NOA Neurooncology Working Group; Canadian Cancer Trials Group (CCTG); EORTC European Organisation for Research and Treatment of Cancer (EORTC); ANOCEF The Association des Neuro-Oncologues d'Expression Française; $T M Z$ temozolomide; $h R T$ hypofractionated radiation therapy 
of age with Eastern Cooperative Oncology Group (ECOG) performance status 0-2 to sRT (60Gy in 30 fractions), hRT (34Gy in 10 fractions), or TMZ. OS was longer in patients $>70$ years of age who were treated with TMZ or hRT compared with those who received sRT [21]. An even more abbreviated course of $25 \mathrm{~Gy}$ in 5 fractions was found to be non-inferior to the $40 \mathrm{~Gy}$ course, but its use is controversial [53-55]. Moreover, in 2019, the coronavirus disease 2019 (COVID-19) pandemic compelled organizations to expeditiously update the existing treatment recommendations for immunosuppressed patients, including elderly patients. Elderly patients infected with COVID-19 experience worse outcome, thereby supporting rationale for a shorter RT treatment schedule to mitigate exposure risk to the virus [56•]. In summary, RT for eGBM improves OS compared to best supportive care without compromising QoL or cognition and hRT should be considered in patients $>65-70$ years of age. Withholding RT can be justified in a subset of eGBM with $\mathrm{m} M G M T$ tumors and poor KPS. This is further discussed in the monotherapy section.

\section{Combination Chemoradiation Therapy with TMZ}

A recent retrospective study of all GBM patients from the US National Cancer Database between 2005 and 2016 showed that older age negatively impacts the likelihood of receiving combination chemoradiation [7]. Other negative impact factors associated with older age include Medicaid or no insurance, lower income bracket, and existing comorbidities [7]. Growing evidence supports the use of aggressive treatment with maximal safe resection, sRT, and chemotherapy in select eGBM with good functional status [7, 12, $36,57 \bullet, 58]$, but has not been prospectively studied. In 2008, Minniti et al. conducted a single-arm prospective study of 32 eGBM age $>70$ years using combination therapy with sRT and reported median OS of 10.6 months [59]. In 2009, a long-term 5-year follow-up subgroup analyses of the European Organisation for Research and Treatment of Cancer (EORTC) 26981-National Cancer Institute of Canada (NCIC) CE.3 trial found that combination chemoradiation conferred a survival advantage compared to RT alone [49]. However, this benefit diminished with increasing age [49, 60 ], with less overall benefit in patients $>60$ years of age compared to RT alone (10.9 months vs. 11.8 months) [49]. At 2-year follow-up, the survival benefit with combined therapy was $21.8 \%$ vs $5.7 \%$, but the benefit was marginal at 5 -year follow-up (6.6 vs. 0\%) [49]. In a large retrospective review conducted by Pretanvil et al. of 2670 eGBM $>70$ years diagnosed between 2005 and 2010, combination chemoradiation resulted in the longer OS compared to surgery and RT or surgery alone in eGBM (8 months, 5 months, and 3 months, respectively) [12]. In a recent 2020 meta-analysis of treatment for nd eGBM, Hanna et al. found strong evidence for increased OS with combined chemoradiation compared to RT alone [57•].

In contrast, other studies found no survival benefit with combination therapy in eGBM [61]. In a 2012 10-year retrospective study, Cao et al. reported decreased survival in eGBM with combined chemoradiation compared to hRT followed by salvage TMZ (6.9 months vs. 13.3 months) [61]. Minniti et al. conducted a retrospective study of 127 eGBM comparing hRT to sRT in combination therapy [62]. Results of this study showed similar median OS (6.7 months vs. 5.6 months, respectively) [62], but significantly increased neurotoxicities and poorer performance status in the patients who received sRT [62]. Additional studies report increased toxicity from combination therapy with sRT [24, 57•, 63], with $42 \%$ of elderly patients developing neurocognitive decline [63] and Common Terminology Criteria for Adverse Events (CTCAE) grade 3 or 4 toxicities compared to treatment with RT alone [24]. In 2017, the Canadian Cancer Trials Group (CCTG)/EORTC 26062 trial found that combinatorial hRT and TMZ improves survival over hRT alone [64] and can be considered for eGBM with good performance status.

\section{Monotherapy with RT or TMZ}

eGBM patients with poor KPS may not be able to tolerate combined chemoradiation. For these patients, monotherapy with TMZ or RT may be warranted. Evidence derived from multiple prospective studies advocate for the tailoring of monotherapy based on $M G M T$ promoter methylation status [26, 54, 65-68]. The 2011 ANOCEF trial found that TMZ monotherapy in patients $>70$ years of age was well tolerated and resulted in improved median OS compared to supportive care alone ( 25 weeks vs. 12-16 weeks), with greater survival benefit in $\mathrm{m} M G M T$ eGBM compared to uMGMT eGBM [69]. Subgroup analyses from the 2012 Nordic and NOA-08 trials also argue for the use of TMZ monotherapy in mMGMT eGBM [20, 21]. The Nordic trial randomized patients to three different arms of sRT, hRT, or TMZ ( $200 \mathrm{mg} / \mathrm{m}^{2}$ for 5 consecutive days over 28-day cycles) [21]. Results showed that both TMZ alone and hRT alone were superior to $\mathrm{SRT}$ for eGBM $>70$ years of age (TMZ vs sRT HR $=0.35(0.21-0.56), p<0.0001)$ [21]. The NOA08 non-inferiority trial (NCT01502241) randomized 371 patients $\geq 65$ years of age with GBM $(n=331)$ or anaplastic astrocytoma $(n=40)$ and KPS of $>60$ to dose-dense (DD) TMZ $\left(100 \mathrm{mg} / \mathrm{m}^{2}, 1\right.$ week on/1 week off) or sRT (30 fractions of 1.8 to 2.0 Gy delivered over $6-7$ weeks to a total dose $60 \mathrm{~Gy}$ ) [20]. DD adjuvant TMZ was found to be noninferior to sRT (OS 8.6 months vs. 9.6 months) [20]. Taken together, results from these studies suggest that single-agent TMZ is a reasonable alternative therapy for $\mathrm{m} M G M T$ eGBM with poor KPS [69] and significant medical comorbidities. More recently, methylation profiling has garnered attention 
for more accurate classification of gliomas as shown in the intriguing findings from the newly published long-term follow-up data of the NOA-08 trial; the mMGMT receptor tyrosine kinase (RTK) II methylation class of GBM showed the greatest benefit from TMZ [70••]. The authors also concluded that RTK I and mesenchymal methylation classes did not derive benefit from TMZ and alternative therapies should be considered for these patients [70••]. However, attention should be drawn to the lack of consistency in the dosing and duration of TMZ among these studies. Furthermore, survival outcomes on single-agent TMZ vs. combined chemoradiation have not been studied.

For uMGMT eGBM, RT monotherapy is favored over single-agent TMZ $[20,54,71]$ and is an acceptable alternative to combination chemoradiation [20]. The 2016 Project of Emilia Romagna Region on Neuro-Oncology (PERNO) prospective study included 76 patients $>70$ years of age and found less survival benefit with uMGMT compared to $\mathrm{m} M G M T$ tumors treated with RT/TMZ (8.8 months vs. 17.2 months) [72]. The CCTG/EORTC 26062 trial showed similar findings of decreased survival benefit with the addition of TMZ in uMGMT compared to mMGMT eGBM [64]. Recent literature provides justification to withhold TMZ for eGBM with uMGMT tumors during the COVID-19 pandemic [73].

Notably, though $M G M T$ promoter methylation status is essential for treatment decision-making in eGBM, consensus is lacking on the optimal testing method [71], threshold or cut-off values, and identification of the specific $\mathrm{CpG}$ sites that are required to be methylated to induce the transcriptional silencing $[68,71]$. Additionally, methylation-specific assays can be qualitative or quantitative and can differ in their analyses of distinct $\mathrm{CpG}$ sites [68], which can lead to variable results, particularly with limited biopsy tissue samples. We suggest confirming MGMT promoter methylation test result in eGBM by at least two independent assays when methylation is not detected.

\section{Bevacizumab (BEV)}

BEV, a VEGF monoclonal antibody, was studied in a phase 2 trial in combination with RT in GBMs [74]. The Phase 2 Avastin Plus Radiotherapy in Elderly Patients with Glioblastoma (ARTE) trial investigated survival benefit with the addition of BEV to hRT in patients $>65$ years of age with nd eGBM [75]. Findings from this study recapitulated prior trial results of the addition of BEV for progressive GBMs [76-78], improving PFS, but not OS (PFS-3 of 7.6 vs. 4.8 months, $p=0.003$ ) [79]. Early data from a phase 2 clinical trial investigating the use of BEV in combination with TMZ for eGBM (NCT01149850) [80] showed promising results with possible survival benefit and good tolerability [81]. However, a recent 2020 meta-analysis on nd eGBM found low evidence for BEV use in this patient population with higher risk of adverse events [57•]. The neuropsychiatric adverse events and cognitive decline observed in the eGBM patients who received BEV [75] were consistent with the decline in QoL and inferior cognitive functioning reported in the RTOG 0825 trial [76].

\section{Tumor-Treating Fields (TTF)}

TTF deliver low-intensity alternating electric fields and antimitotic activity through a portable medical device $[82,83]$. TTF are FDA approved for nd GBM based on results from the multicenter, prospective, randomized phase $3 \mathrm{EF}-14$ trial [83]. Combination therapy followed by TTF improves survival by nearly 5 months compared to TMZ alone (20.5 months vs. 15.6 months) [83]. A post-hoc analysis of the 134 eGBM $\geq 65$ years of age in the EF-14 study showed improved median OS of 17.4 months vs. 13.7 months with the addition of TTF to TMZ compared to TMZ alone [82]. Another post-hoc analysis of the EF-14 trial showed that the greatest survival advantage was associated with eGBM $>65$ years of age and the addition of TTF resulted in a gain of 1.75 incremental life years compared to TMZ alone with good tolerability [84]. Recently, a 2020 large retrospective study of 11,029 patients treated with TTF ( $26 \%$ of whom were elderly) found that eGBM experienced the lowest rate of electric and heat sensations, headache, and discomfort [85].

\section{Future Directions}

eGBM patients are undoubtedly a special patient population with a unique set of therapeutic challenges. Recognition of the higher risk for neurocognitive toxicities in eGBM is imperative, but geriatric assessments (GAs) are lacking in eGBM clinical trials [86]. The comprehensive geriatric assessment (CGA) is in use for elderly patients with cancer, but not GBM [87]. A recent 2019 retrospective study showed that the CGA is prognostic for eGBM and may potentially inform which patients will benefit from combined chemoradiation [87]. In 2020, the first prospective study evaluating the utility of neurologic-based GAs was conducted in the geriatric assessment for OLDEr patients with Glioblastoma within Neuro-oncology clinics (GOLDEN) study and found that GAs provide prognostic value and are feasible to perform [88].

fNovel therapeutic approaches are needed in eGBM as prognosis remains dismal. Immunotherapy has revolutionized cancer therapy, but has yet to show survival benefit in GBM or eGBM [37]. The Nivolumab and Temozolomide Versus Temozolomide Alone in Newly Diagnosed Elderly Patients with GBM (NUTMEG) trial is phase 2 study investigating the effects of combinatorial adjuvant nivolumab and 
TMZ vs. TMZ alone in nd eGBM (NCT04195139) [89]. The impact of immunosenescence in eGBM [90], tumoral heterogeneity, and tumor microenvironment immunosuppression [91] are challenges that are paramount to overcome in order to increase responsiveness to immunotherapy [90]. Moreover, it remains unclear which subgroups of GBM patients may benefit from immunotherapy. High tumor mutational burden (TMB) in comparison to intermediate or low mutational burden may be associated with increased sensitivity to anti-programmed death-ligand 1 (PD-L1) inhibitors in other cancers [92], but immune checkpoint blockade has not shown benefit in GBM [93, 94]. However, isolated cases in non-elderly GBM patients have shown success $[95,96]$. Advances in molecular profiling may identify biomarkers of checkpoint sensitivity and inform which subgroups of eGBM may benefit from immunotherapy.

Targeted therapy driven by enhanced understanding of the molecular biology of GBM is an active area of research with many new innovative clinical trial designs utilizing new data; enrollment of eGBM patients on these trials should be encouraged. For example, an ongoing phase $1 / 2$ TERT derived vaccine trial (NCT04280848) investigating telomerase-targeting GBM peptides is currently underway, and patients up to 75 years of age are eligible [97]. Similarly, CDK inhibitors may play a role in eGBM. Preliminary results from a phase 2/3 trial studying abemaciclib in GBM showed increased PFS compared to control (NCT02977780 "INdividualized Screening Trial of Innovative Glioblastoma Therapy (INSIGhT)") trial [98-100].

\section{Conclusion}

Elderly patients with newly diagnosed GBMs warrant special attention in their treatment approach. High functioning eGBM patients should be considered for combined chemoradiation therapy. Those with poor functioning can be stratified for monotherapy based on $M G M T$ promoter methylation status. For mMGMT tumors, single-agent TMZ can be considered, while hypofractionated RT alone may be sufficient for uMGMT tumors. Despite treatment (combination or monotherapy), prognosis of eGBM remains grim, and better understanding of the molecular signature of these tumors is of paramount importance as it will help elucidate the causes for age-specific different outcome and open the door to development of new novel therapies.

Acknowledgements We thank the William Rhodes and Louise TilzerRhodes Center for Glioblastoma at New York-Presbyterian Hospital for their support.

Data Availability (data transparency) The authors confirm that all data and materials support published claims and comply with field standards.
Code Availability Not applicable.

\section{Declarations}

Ethics Approval Not applicable.

Conflict of Interest/Competing Interests The authors declare no competing interests.

Human and Animal Rights and Informed Consent This article does not contain any studies with human or animal subjects.

Consent to Participate Not applicable.

Consent for Publication Not applicable.

\section{References}

Papers of particular interest, published recently, have been highlighted as:

- Of importance

$\bullet$ Of major importance

1. Ostrom QT, Patil N, Cioffi G, Waite K, Kruchko C, BarnholtzSloan JS. CBTRUS statistical report: primary brain and other central nervous system tumors diagnosed in the united states in 2013-2017. Neuro Oncol. 2020;22(12 Suppl 2):iv1-iv96. https:// doi.org/10.1093/neuonc/noaa200

2. Stupp R, Mason WP, van den Bent MJ, Weller M, Fisher B, Taphoorn MJ, et al. Radiotherapy plus concomitant and adjuvant temozolomide for glioblastoma. N Engl J Med. 2005;352(10):987-96. https://doi.org/10.1056/NEJMoa043330.

3. Curran WJ Jr, Scott CB, Horton J, Nelson JS, Weinstein AS, Fischbach AJ, et al. Recursive partitioning analysis of prognostic factors in three Radiation Therapy Oncology Group malignant glioma trials. J Natl Cancer Inst. 1993;85(9):704-10. https://doi. org/10.1093/jnci/85.9.704.

4. Iwamoto FM, Reiner AS, Panageas KS, Elkin EB, Abrey LE. Patterns of care in elderly glioblastoma patients. Ann Neurol. 2008;64(6):628-34. https://doi.org/10.1002/ana.21521.

5. Aapro MS, Kohne CH, Cohen HJ, Extermann M. Never too old? Age should not be a barrier to enrollment in cancer clinical trials. Oncologist. 2005;10(3):198-204. https://doi.org/10.1634/theon cologist.10-3-198.

6. Flanigan PM, Jahangiri A, Kuang R, Truong A, Choi S, Chou A, et al. Developing an algorithm for optimizing care of elderly patients with glioblastoma. Neurosurgery. 2018;82(1):64-75. https://doi.org/10.1093/neuros/nyx148.

7. Lu VM, Lewis CT, Esquenazi Y. Geographic and socioeconomic considerations for glioblastoma treatment in the elderly at a national level: a US perspective. Neurooncol Pract. 2020;7(5):522-30. https://doi.org/10.1093/nop/npaa029.

8. Scoccianti S, Magrini SM, Ricardi U, Detti B, Buglione M, Sotti $\mathrm{G}$, et al. Patterns of care and survival in a retrospective analysis of 1059 patients with glioblastoma multiforme treated between 2002 and 2007: a multicenter study by the Central Nervous System Study Group of Airo (italian Association of Radiation Oncology). Neurosurgery. 2010;67(2):446-58. https://doi.org/ 10.1227/01.NEU.0000371990.86656.E8.

9. Barnholtz-Sloan JS, Williams VL, Maldonado JL, Shahani D, Stockwell HG, Chamberlain M, et al. Patterns of care and 
outcomes among elderly individuals with primary malignant astrocytoma. J Neurosurg. 2008;108(4):642-8. https://doi.org/ 10.3171/JNS/2008/108/4/0642.

10. Lowry JK, Snyder JJ, Lowry PW. Brain tumors in the elderly: recent trends in a Minnesota cohort study. Arch Neurol. 1998;55(7):922-8. https://doi.org/10.1001/archneur.55.7.922.

11. Lorimer CF, Hanna C, Saran F, Chalmers A, Brock J. Challenges to treating older glioblastoma patients: the influence of clinical and tumour characteristics on survival outcomes. Clin Oncol (R Coll Radiol). 2017;29(11):739-47. https://doi.org/10.1016/j. clon.2017.05.010.

12. Pretanvil JA, Salinas IQ, Piccioni DE. Glioblastoma in the elderly: treatment patterns and survival. CNS Oncol. 2017;6(1):19-28. https://doi.org/10.2217/cns-2016-0023.

13. Noushmehr H, Weisenberger DJ, Diefes K, Phillips HS, Pujara $\mathrm{K}$, Berman $\mathrm{BP}$, et al. Identification of a $\mathrm{CpG}$ island methylator phenotype that defines a distinct subgroup of glioma. Cancer Cell. 2010;17(5):510-22. https://doi.org/10.1016/j.ccr.2010.03. 017

14. Lee Y, Scheck AC, Cloughesy TF, Lai A, Dong J, Farooqi HK, et al. Gene expression analysis of glioblastomas identifies the major molecular basis for the prognostic benefit of younger age. BMC Med Genomics. 2008;1:52. https://doi.org/10.1186/ 1755-8794-1-52.

15. Louis DN, Perry A, Wesseling P, Brat DJ, Cree IA, FigarellaBranger D, et al. The 2021 WHO classification of tumors of the central nervous system: a summary. Neuro Oncol. 2021;23(8):1231-51. https://doi.org/10.1093/neuonc/noab106.

16. Yan H, Parsons DW, Jin G, McLendon R, Rasheed BA, Yuan $\mathrm{W}$, et al. IDH1 and IDH2 mutations in gliomas. N Engl J Med. 2009;360(8):765-73. https://doi.org/10.1056/NEJMoa0808710.

17. Nobusawa S, Watanabe T, Kleihues P, Ohgaki H. IDH1 mutations as molecular signature and predictive factor of secondary glioblastomas. Clin Cancer Res. 2009;15(19):6002-7. https:// doi.org/10.1158/1078-0432.CCR-09-0715.

18. Wiestler B, Claus R, Hartlieb SA, Schliesser MG, Weiss EK, Hielscher T, et al. Malignant astrocytomas of elderly patients lack favorable molecular markers: an analysis of the NOA-08 study collective. Neuro Oncol. 2013;15(8):1017-26. https://doi. org/10.1093/neuonc/not043.

19. Ostrom QT, Kinnersley B, Armstrong G, Rice T, Chen Y, Wiencke JK, et al. Age-specific genome-wide association study in glioblastoma identifies increased proportion of 'lower grade glioma'-like features associated with younger age. Int J Cancer. 2018;143(10):2359-66. https://doi.org/10.1002/ijc.31759.

20. Wick W, Platten M, Meisner C, Felsberg J, Tabatabai G, Simon $\mathrm{M}$, et al. Temozolomide chemotherapy alone versus radiotherapy alone for malignant astrocytoma in the elderly: the NOA-08 randomised, phase 3 trial. Lancet Oncol. 2012;13(7):707-15. https://doi.org/10.1016/S1470-2045(12)70164-X.

21. Malmström A, Grønberg BH, Marosi C, Stupp R, Frappaz D, Schultz H, et al. Temozolomide versus standard 6-week radiotherapy versus hypofractionated radiotherapy in patients older than 60 years with glioblastoma: the Nordic randomised, phase 3 trial. Lancet Oncol. 2012;13(9):916-26. https://doi.org/10.1016/ S1470-2045(12)70265-6.

22. DeWitt JC, Jordan JT, Frosch MP, Samore WR, Iafrate AJ, Louis DN, et al. Cost-effectiveness of IDH testing in diffuse gliomas according to the 2016 WHO classification of tumors of the central nervous system recommendations. Neuro Oncol. 2017;19(12):1640-50. https://doi.org/10.1093/neuonc/nox120.

23. Hegi ME, Diserens AC, Gorlia T, Hamou MF, de Tribolet N, Weller M, et al. MGMT gene silencing and benefit from temozolomide in glioblastoma. N Engl J Med. 2005;352(10):997-1003. https://doi.org/10.1056/NEJMoa043331.
24. Sijben AE, McIntyre JB, Roldán GB, Easaw JC, Yan E, Forsyth $\mathrm{PA}$, et al. Toxicity from chemoradiotherapy in older patients with glioblastoma multiforme. J Neurooncol. 2008;89(1):97-103. https://doi.org/10.1007/s11060-008-9593-6.

25. Gerstner ER, Yip S, Wang DL, Louis DN, Iafrate AJ, Batchelor TT. Mgmt methylation is a prognostic biomarker in elderly patients with newly diagnosed glioblastoma. Neurology. 2009;73(18):1509-10. https://doi.org/10.1212/WNL.0b013 e3181bf9907.

26. Holdhoff M, Chamberlain MC. Controversies in the treatment of elderly patients with newly diagnosed glioblastoma. J Natl Compr Canc Netw. 2013;11(9):1165-72; quiz 73. https://doi.org/ 10.6004/jnccn.2013.0134

27. Ene CI, Cimino PJ, Fine HA, Holland EC. Incorporating genomic signatures into surgical and medical decision-making for elderly glioblastoma patients. Neurosurg Focus. 2020;49(4):E11. https:// doi.org/10.3171/2020.7.FOCUS20418.

28. Batchelor TT, Betensky RA, Esposito JM, Pham LD, Dorfman MV, Piscatelli N, et al. Age-dependent prognostic effects of genetic alterations in glioblastoma. Clin Cancer Res. 2004;10(1 Pt 1):228-33. https://doi.org/10.1158/1078-0432.ccr-0841-3.

29. Fukai J, Arita H, Umehara T, Yoshioka E, Shofuda T, Kanematsu D, et al. Molecular characteristics and clinical outcomes of elderly patients with IDH-wildtype glioblastomas: comparative study of older and younger cases in Kansai Network cohort. Brain Tumor Pathol. 2020;37(2):50-9. https://doi.org/10.1007/ s10014-020-00363-1.

30. Simon M, Hosen I, Gousias K, Rachakonda S, Heidenreich B, Gessi M, et al. TERT promoter mutations: a novel independent prognostic factor in primary glioblastomas. Neuro Oncol. 2015;17(1):45-52. https://doi.org/10.1093/neuonc/nou158.

31. Clarke JW, Chang EL, Levin VA, Mayr NA, Hong E, Cavaliere R, et al. Optimizing radiotherapy schedules for elderly glioblastoma multiforme patients. Expert Rev Anticancer Ther. 2008;8(5):733-41. https://doi.org/10.1586/14737140.8.5.733.

32. Eckel-Passow JE, Lachance DH, Molinaro AM, Walsh KM, Decker PA, Sicotte H, et al. Glioma groups based on 1p/19q, IDH, and TERT promoter mutations in tumors. N Engl J Med. 2015;372(26):2499-508. https://doi.org/10.1056/NEJMoa1407 279.

33. Sasaki T, Fukai J, Kodama Y, Hirose T, Okita Y, Moriuchi $\mathrm{S}$, et al. Characteristics and outcomes of elderly patients with diffuse gliomas: a multi-institutional cohort study by Kansai molecular diagnosis network for CNS Tumors. J Neurooncol. 2018;140(2):329-39. https://doi.org/10.1007/ s11060-018-2957-7.

34. Brat DJ, Aldape K, Colman H, Holland EC, Louis DN, Jenkins $\mathrm{RB}$, et al. cIMPACT-NOW update 3: recommended diagnostic criteria for "diffuse astrocytic glioma, IDH-wildtype, with molecular features of glioblastoma, WHO grade IV." Acta Neuropathol. 2018;136(5):805-10. https://doi.org/10.1007/ s00401-018-1913-0.

35. Pekmezci M, Rice T, Molinaro AM, Walsh KM, Decker PA, Hansen H, et al. Adult infiltrating gliomas with WHO 2016 integrated diagnosis: additional prognostic roles of ATRX and TERT. Acta Neuropathol. 2017;133(6):1001-16. https://doi.org/ 10.1007/s00401-017-1690-1.

36. Scott JG, Bauchet L, Fraum TJ, Nayak L, Cooper AR, Chao ST, et al. Recursive partitioning analysis of prognostic factors for glioblastoma patients aged 70 years or older. Cancer. 2012;118(22):5595-600. https://doi.org/10.1002/cncr.27570.

37. Babu R, Komisarow JM, Agarwal VJ, Rahimpour S, Iyer A, Britt $\mathrm{D}$, et al. Glioblastoma in the elderly: the effect of aggressive and modern therapies on survival. J Neurosurg. 2016;124(4):9981007. https://doi.org/10.3171/2015.4.JNS142200. 
38. Chaichana KL, Garzon-Muvdi T, Parker S, Weingart JD, Olivi A, Bennett R, et al. Supratentorial glioblastoma multiforme: the role of surgical resection versus biopsy among older patients. Ann Surg Oncol. 2011;18(1):239-45. https://doi.org/10.1245/ s10434-010-1242-6.

39. Almenawer SA, Badhiwala JH, Alhazzani W, Greenspoon J, Farrokhyar F, Yarascavitch B, et al. Biopsy versus partial versus gross total resection in older patients with high-grade glioma: a systematic review and meta-analysis. Neuro Oncol. 2015;17(6):868-81. https://doi.org/10.1093/neuonc/nou349.

40. Vuorinen V, Hinkka S, Farkkila M, Jaaskelainen J. Debulking or biopsy of malignant glioma in elderly people - a randomised study. Acta Neurochir (Wien). 2003;145(1):5-10. https://doi.org/ 10.1007/s00701-002-1030-6.

41. Hoffermann M, Bruckmann L, Kariem Mahdy A, Asslaber M, Payer F, von Campe G. Treatment results and outcome in elderly patients with glioblastoma multiforme-a retrospective single institution analysis. Clin Neurol Neurosurg. 2015;128:60-9. https://doi.org/10.1016/j.clineuro.2014.11.006.

42. Molinaro AM, Hervey-Jumper S, Morshed RA, Young J, Han SJ, Chunduru P, et al. Association of maximal extent of resection of contrast-enhanced and non-contrast-enhanced tumor with survival within molecular subgroups of patients with newly diagnosed glioblastoma. JAMA Oncol. 2020;6(4):495-503. https:// doi.org/10.1001/jamaoncol.2019.6143.

43. Noorbakhsh A, Tang JA, Marcus LP, McCutcheon B, Gonda DD, Schallhorn CS, et al. Gross-total resection outcomes in an elderly population with glioblastoma: a SEER-based analysis. J Neurosurg. 2014;120(1):31-9. https://doi.org/10.3171/2013.9. JNS13877.

44. Ewelt C, Goeppert M, Rapp M, Steiger HJ, Stummer W, Sabel M. Glioblastoma multiforme of the elderly: the prognostic effect of resection on survival. J Neurooncol. 2011;103(3):611-8. https://doi.org/10.1007/s11060-010-0429-9.

45. Oszvald A, Guresir E, Setzer M, Vatter H, Senft C, Seifert $\mathrm{V}$, et al. Glioblastoma therapy in the elderly and the importance of the extent of resection regardless of age. J Neurosurg. 2012;116(2):357-64. https://doi.org/10.3171/2011.8.JNS10 2114.

46. Heiland DH, Haaker G, Watzlawick R, Delev D, Masalha W, Franco P, et al. One decade of glioblastoma multiforme surgery in 342 elderly patients: what have we learned? J Neurooncol. 2018;140(2):385-91. https://doi.org/10.1007/ s11060-018-2964-8.

47. Domino JS, Ormond DR, Germano IM, Sami M, Ryken TC, Olson JJ. Cytoreductive surgery in the management of newly diagnosed glioblastoma in adults: a systematic review and evidence-based clinical practice guideline update. J Neurooncol. 2020;150(2):121-42. https://doi.org/10.1007/ s11060-020-03606-5.

48. Stark AM, Hedderich J, Held-Feindt J, Mehdorn HM. Glioblastoma--the consequences of advanced patient age on treatment and survival. Neurosurg Rev. 2007;30(1):56-61; discussion-2. https://doi.org/10.1007/s10143-006-0051-7

49. Stupp R, Hegi ME, Mason WP, van den Bent MJ, Taphoorn MJ, Janzer RC, et al. Effects of radiotherapy with concomitant and adjuvant temozolomide versus radiotherapy alone on survival in glioblastoma in a randomised phase III study: 5-year analysis of the EORTC-NCIC trial. Lancet Oncol. 2009;10(5):459-66. https://doi.org/10.1016/S1470-2045(09)70025-7.

50. Keime-Guibert F, Chinot O, Taillandier L, Cartalat-Carel S, Frenay M, Kantor G, et al. Radiotherapy for glioblastoma in the elderly. N Engl J Med. 2007;356(15):1527-35. https://doi.org/ 10.1056/NEJMoa065901.

51. Roa W, Brasher PM, Bauman G, Anthes M, Bruera E, Chan A, et al. Abbreviated course of radiation therapy in older patients with glioblastoma multiforme: a prospective randomized clinical trial. J Clin Oncol. 2004;22(9):1583-8. https://doi.org/10.1200/ JCO.2004.06.082.

52. Meckling S, Dold O, Forsyth PA, Brasher P, Hagen NA. Malignant supratentorial glioma in the elderly: is radiotherapy useful? Neurology. 1996;47(4):901-5. https://doi.org/10.1212/wnl.47.4. 901.

53. Roa W, Kepka L, Kumar N, Sinaika V, Matiello J, Lomidze $\mathrm{D}$, et al. International atomic energy agency randomized phase III study of radiation therapy in elderly and/or frail patients with newly diagnosed glioblastoma multiforme. J Clin Oncol. 2015;33(35):4145-50. https://doi.org/10.1200/jco.2015.62.6606.

54. Weller M, van den Bent M, Tonn JC, Stupp R, Preusser M, Cohen-Jonathan-Moyal E, et al. European Association for Neuro-Oncology (EANO) guideline on the diagnosis and treatment of adult astrocytic and oligodendroglial gliomas. Lancet Oncol. 2017;18(6):e315-29. https://doi.org/10.1016/S14702045(17)30194-8.

55. Wick A, Kessler T, Elia AEH, Winkler F, Batchelor TT, Platten M, et al. Glioblastoma in elderly patients: solid conclusions built on shifting sand? Neuro Oncol. 2018;20(2):174-83. https://doi. org/10.1093/neuonc/nox133.

56.• Tabrizi S, Trippa L, Cagney D, Tanguturi S, Ventz S, Fell G, et al. A quantitative framework for modeling COVID-19 risk during adjuvant therapy using published randomized trials of glioblastoma in the elderly. Neuro Oncol. 2020. https://doi.org/ $10.1093 /$ neuonc/noaa111. This publication is of importance due to the recent COVID-19 pandemic and risk reduction to the virus is crucial for immunocompromised eGBM patients.

57. Hanna C, Lawrie TA, Rogozinska E, Kernohan A, Jefferies S, Bulbeck H, et al. Treatment of newly diagnosed glioblastoma in the elderly: a network meta-analysis. Cochrane Database Syst Rev. 2020;3:CD013261. https://doi.org/10.1002/14651858. CD013261.pub2. This publication is of importance because it identifies high-level evidence for increased overall survival with chemoradiation compared to radition therapy in eGBM. Findings from this meta-analysis also shows no difference in quality of life with temozolomide compared to radiation therapy.

58. Fiorentino A, Balducci M, De Bonis P, Chiesa S, De Filippo L, Mangiola A, et al. Can elderly patients with newly diagnosed glioblastoma be enrolled in radiochemotherapy trials? Am J Clin Oncol. 2015;38(1):23-7. https://doi.org/10.1097/COC.0b013 e3182868ea2.

59. Minniti G, De Sanctis V, Muni R, Filippone F, Bozzao A, Valeriani M, et al. Radiotherapy plus concomitant and adjuvant temozolomide for glioblastoma in elderly patients. J Neurooncol. 2008;88(1):97-103. https://doi.org/10.1007/s11060-008-9538-0.

60. Laperriere N, Weller M, Stupp R, Perry JR, Brandes AA, Wick $\mathrm{W}$, et al. Optimal management of elderly patients with glioblastoma. Cancer Treat Rev. 2013;39(4):350-7. https://doi.org/10. 1016/j.ctrv.2012.05.008.

61. Cao JQ, Fisher BJ, Bauman GS, Megyesi JF, Watling CJ, Macdonald DR. Hypofractionated radiotherapy with or without concurrent temozolomide in elderly patients with glioblastoma multiforme: a review of ten-year single institutional experience. J Neurooncol. 2012;107(2):395-405. https://doi.org/10.1007/ s11060-011-0766-3.

62. Minniti G, Scaringi C, Lanzetta G, Terrenato I, Esposito V, Arcella A, et al. Standard (60 Gy) or short-course (40 Gy) irradiation plus concomitant and adjuvant temozolomide for elderly patients with glioblastoma: a propensity-matched analysis. Int J Radiat Oncol Biol Phys. 2015;91(1):109-15. https://doi.org/10. 1016/j.ijrobp.2014.09.013.

63. Brandes AA, Franceschi E, Tosoni A, Benevento F, Scopece $\mathrm{L}$, Mazzocchi $\mathrm{V}$, et al. Temozolomide concomitant and 
adjuvant to radiotherapy in elderly patients with glioblastoma: correlation with MGMT promoter methylation status. Cancer. 2009;115(15):3512-8. https://doi.org/10.1002/cncr.24406.

64. Perry JR, Laperriere N, O'Callaghan CJ, Brandes AA, Menten J, Phillips C, et al. Short-course radiation plus temozolomide in elderly patients with glioblastoma. N Engl J Med. 2017;376(11):1027-37. https://doi.org/10.1056/NEJMoa1611 977.

65. Reifenberger G, Hentschel B, Felsberg J, Schackert G, Simon M, Schnell O, et al. Predictive impact of MGMT promoter methylation in glioblastoma of the elderly. Int $\mathrm{J}$ Cancer. 2012;131(6):1342-50. https://doi.org/10.1002/ijc.27385.

66. Mason M, Laperriere N, Wick W, Reardon DA, Malmstrom A, Hovey E, et al. Glioblastoma in the elderly: making sense of the evidence. Neurooncol Pract. 2016;3(2):77-86. https://doi.org/ 10.1093/nop/npv027.

67. Zarnett OJ, Sahgal A, Gosio J, Perry J, Berger MS, Chang S, et al. Treatment of elderly patients with glioblastoma: a systematic evidence-based analysis. JAMA Neurol. 2015;72(5):589-96. https://doi.org/10.1001/jamaneurol.2014.3739.

68. Wick W, Weller M, van den Bent M, Sanson M, Weiler M, von Deimling A, et al. MGMT testing-the challenges for biomarkerbased glioma treatment. Nat Rev Neurol. 2014;10(7):372-85. https://doi.org/10.1038/nrneurol.2014.100.

69. Pérez-Larraya JG, Ducray F, Chinot O, Catry-Thomas I, Taillandier L, Guillamo J-S, et al. Temozolomide in elderly patients with newly diagnosed glioblastoma and poor performance status: an ANOCEF phase II trial. J Clin Oncol. 2011;29(22):3050-5. https://doi.org/10.1200/jco.2011.34.8086.

70.• Wick A, Kessler T, Platten M, Meisner C, Bamberg M, Herrlinger $\mathrm{U}$, et al. Superiority of temozolomide over radiotherapy for elderly patients with RTK II methylation class, MGMT promoter methylated malignant astrocytoma. Neuro Oncol. 2020;22(8):1162-72. https://doi.org/10.1093/neuonc/noaa033. This publication is of outstanding importance due to the long-term follow-up of median 7.5 years and use of methylation profiling for more accurate glioma classification. This publication identifies a subset of eGBM (RTK II) that is more sensitive to TMZ.

71. Brandner S, McAleenan A, Kelly C, Spiga F, Cheng HY, Dawson $\mathrm{S}$, et al. MGMT promoter methylation testing to predict overall survival in people with glioblastoma treated with temozolomide: a comprehensive meta-analysis based on a Cochrane Review. Neuro Oncol. 2021. https://doi.org/10.1093/neuonc/noab105.

72. Franceschi E, Depenni R, Paccapelo A, Ermani M, Faedi M, Sturiale $\mathrm{C}$, et al. Which elderly newly diagnosed glioblastoma patients can benefit from radiotherapy and temozolomide? A PERNO prospective study. J Neurooncol. 2016;128(1):157-62. https://doi.org/10.1007/s11060-016-2093-1.

73. Bernhardt D, Wick W, Weiss SE, Sahgal A, Lo SS, Suh JH, et al. Neuro-oncology management during the COVID-19 pandemic with a focus on WHO grade III and IV gliomas. Neuro Oncol. 2020. https://doi.org/10.1093/neuonc/noaa113.

74. Friedman HS, Prados MD, Wen PY, Mikkelsen T, Schiff $\mathrm{D}$, Abrey LE, et al. Bevacizumab alone and in combination with irinotecan in recurrent glioblastoma. J Clin Oncol. 2009;27(28):4733-40. https://doi.org/10.1200/JCO.2008.19. 8721.

75. Wirsching HG, Tabatabai G, Roelcke U, Hottinger AF, Jorger F, Schmid A, et al. Bevacizumab plus hypofractionated radiotherapy versus radiotherapy alone in elderly patients with glioblastoma: the randomized, open-label, phase II ARTE trial. Ann Oncol. 2018;29(6):1423-30. https://doi.org/10.1093/annonc/ mdy 120.

76. Gilbert MR, Dignam JJ, Armstrong TS, Wefel JS, Blumenthal DT, Vogelbaum MA, et al. A randomized trial of bevacizumab for newly diagnosed glioblastoma. N Engl J Med. 2014;370(8):699-708. https://doi.org/10.1056/NEJMoa1308 573.

77. Chinot OL, Wick W, Mason W, Henriksson R, Saran F, Nishikawa R, et al. Bevacizumab plus radiotherapy-temozolomide for newly diagnosed glioblastoma. N Engl J Med. 2014;370(8):709-22. https://doi.org/10.1056/NEJMoa1308 345.

78. Wick W, Gorlia T, Bendszus M, Taphoorn M, Sahm F, Harting I, et al. Lomustine and Bevacizumab in Progressive Glioblastoma. N Engl J Med. 2017;377(20):1954-63. https://doi.org/10.1056/ NEJMoa1707358.

79. Lai A, Tran A, Nghiemphu PL, Pope WB, Solis OE, Selch M, et al. Phase II study of bevacizumab plus temozolomide during and after radiation therapy for patients with newly diagnosed glioblastoma multiforme. J Clin Oncol. 2011;29(2):142-8. https://doi.org/10.1200/JCO.2010.30.2729.

80. Bevacizumab and temozolomide in treating older patients with newly-diagnosed glioblastoma multiforme or gliosarcoma. https://ClinicalTrials.gov/show/NCT01149850.

81. Nghiemphu PL, Bahng HH, Lai A, Faiq N, Yong WH, Green RM, et al. Phase II trial of bevacizumab and temozolomide for upfront treatment of elderly patients with newly diagnosed glioblastoma. J Clin Oncol. 2017;35(15_suppl):2012. https://doi.org/ 10.1200/JCO.2017.35.15_suppl.2012

82. Ram Z, Kim C-Y, Zhu J-J. Efficacy of tumor treating fields (TTFields) in elderly patients with newly diagnosed glioblastoma (GBM): sub-group analysis of the phase III EF-14 trial. J Clin Oncol. 2020;38(15_suppl):e24019-e. https://doi.org/10. 1200/JCO.2020.38.15_suppl.e24019

83. Stupp R, Taillibert S, Kanner A, Read W, Steinberg D, Lhermitte B, et al. Effect of tumor-treating fields plus maintenance temozolomide vs maintenance temozolomide alone on survival in patients with glioblastoma: a randomized clinical trial. JAMA. 2017;318(23):2306-16. https://doi.org/10.1001/jama.2017. 18718.

84. Guzauskas G, Wang BC, Proescholdt C. HOUT-17. Elderly patients >65years of age with newly diagnosed glioblastoma multiforme gain life time from treatment with tumor treating fields and temozolomide. Neuro-Oncology. 2018;20(suppl_6):vi116-vi. https://doi.org/10.1093/neuonc/ noy 148.485

85. Shi W, Blumenthal DT, Oberheim Bush NA, Kebir S, Lukas RV, Muragaki Y, et al. Global post-marketing safety surveillance of tumor treating fields (TTFields) in patients with high-grade glioma in clinical practice. J Neurooncol. 2020;148(3):489-500. https://doi.org/10.1007/s11060-020-03540-6.

86. Sharma A, Sharma DN, Julka PK, Rath GK. Treatment options in elderly patients with glioblastoma. Lancet Oncol. 2012;13(11):e460-e4601; author reply e1-2. https://doi.org/10. 1016/S1470-2045(12)70459-X

87. Lombardi G, Bergo E, Caccese M, Padovan M, Bellu L, Brunello A, et al. Validation of the comprehensive geriatric assessment as a predictor of mortality in elderly glioblastoma patients. Cancers (Basel). 2019;11(10). https://doi.org/10.3390/cancers11101509

88. Lorimer CF, Walsh G, MacKinnon M, Corbett A, Bedborough $\mathrm{K}$, Greenwood K, et al. Geriatric assessment of glioblastoma patients is feasible and may provide useful prognostic information. Neurooncol Pract. 2020;7(2):176-84. https://doi.org/10. 1093/nop/npz040.

89. Nivolumab and temozolomide versus temozolomide alone in newly diagnosed elderly patients with GBM. https://ClinicalTr ials.gov/show/NCT04195139.

90. Ladomersky E, Scholtens DM, Kocherginsky M, Hibler EA, Bartom ET, Otto-Meyer S, et al. The coincidence between increasing age, immunosuppression, and the incidence of patients with 
glioblastoma. Front Pharmacol. 2019;10:200. https://doi.org/10. 3389/fphar.2019.00200.

91. Majc B, Novak M, Kopitar-Jerala N, Jewett A, Breznik B. Immunotherapy of glioblastoma: current strategies and challenges in tumor model development. Cells. 2021;10(2). https://doi.org/10. 3390/cells10020265

92. Johnson DB, Frampton GM, Rioth MJ, Yusko E, Xu Y, Guo $\mathrm{X}$, et al. Targeted next generation sequencing identifies markers of response to PD-1 blockade. Cancer Immunol Res. 2016;4(11):959-67. https://doi.org/10.1158/2326-6066. CIR-16-0143.

93. Reardon DA, Brandes AA, Omuro A, Mulholland P, Lim M, Wick A, et al. Effect of nivolumab vs bevacizumab in patients with recurrent glioblastoma: the checkmate 143 phase 3 randomized clinical trial. JAMA Oncol. 2020;6(7):1003-10. https:// doi.org/10.1001/jamaoncol.2020.1024.

94. Khasraw M, Reardon DA, Weller M, Sampson JH. PD-1 inhibitors: do they have a future in the treatment of glioblastoma? Clin Cancer Res. 2020;26(20):5287-96. https://doi.org/10.1158/ 1078-0432.CCR-20-1135.

95. Johanns TM, Miller CA, Dorward IG, Tsien C, Chang E, Perry A, et al. Immunogenomics of hypermutated glioblastoma: a patient with germline pole deficiency treated with checkpoint blockade immunotherapy. Cancer Discov. 2016;6(11):1230-6. https://doi.org/10.1158/2159-8290.CD-16-0575.

96. Bouffet E, Larouche V, Campbell BB, Merico D, de Borja R, Aronson M, et al. Immune checkpoint inhibition for hypermutant glioblastoma multiforme resulting from germline biallelic mismatch repair deficiency. J Clin Oncol. 2016;34(19):2206-11. https://doi.org/10.1200/JCO.2016.66.6552.

97. Anticancer therapeutic vaccination using telomerase-derived universal cancer peptides in glioblastoma. https://ClinicalTrials. gov/show/NCT04280848.

98. Individualized screening trial of innovative glioblastoma therapy (INSIGhT). https://ClinicalTrials.gov/show/NCT02977780.

99. Alexander BM, Trippa L, Gaffey S, Arrillaga-Romany IC, Lee EQ, Rinne ML, et al. Individualized screening trial of innovative glioblastoma therapy (INSIGhT): a Bayesian adaptive platform trial to develop precision medicines for patients with glioblastoma. JCO Precis Oncol. 2019;3. https://doi.org/10.1200/PO.18. 00071

100. Wen P, Trippa L, Lee E, Fell G, Rahman R, Arrillaga-Romany I, et al. CTNI-12. Preliminary results of the abemaciclib arm in the individualized screening trial of innovative glioblastoma therapy (INSIGHT): a phase II PLATFORM TRIAL USING BAYESIAN ADAPTIVE RANDOMIZATION. Neuro-Oncol. 2020;22(Supplement_2):ii44-ii. https://doi.org/10.1093/neuonc/ noaa2 15.179

Publisher's Note Springer Nature remains neutral with regard to jurisdictional claims in published maps and institutional affiliations. 